\title{
Dimensões da competência em informação: reflexões frente aos movimentos de infodemia e desinformação na pandemia da Covid-19
}

\author{
Dimensions of information competence: reflections on the \\ movements of infodemia and disinformation in the pandemic of \\ Covid-19
}

\author{
Marta Leandro da Mata ${ }^{a}$ \\ Maira Cristina Grigoleto ${ }^{a}$ \\ Mariana Lousadab, * (D)
}

\begin{abstract}
RESUMO: Este artigo tem como objetivo refletir, com base na Sociologia da Ciência e na Ciência da Informação, sobre as condições de produção, divulgação e validação de enunciados, discursos e fatos científicos dentro e fora dos laboratórios. Em continuidade, pretendeu-se abordar a informação na sociedade contemporânea, apresentando as concepções de infodemia e desinformação, bem como apresentar as possíveis formas de mobilização dos indivíduos por meio das dimensões da competência em informação frente à pandemia da COVID-19. No que diz respeito aos procedimentos metodológicos, essa pesquisa se caracteriza quanto aos objetivos como exploratória, já no que se refere aos procedimentos, utilizou-se a pesquisa bibliográfica. A partir dos dados analisados, inferimos que a pandemia demonstrou que uma parcela significativa da população está vulnerável a infodemia e a desinformação. As fontes de informação institucionalizadas são o melhor canal de comunicação para reverter essa situação. Conclui-se que, torna-se cada vez mais urgente fomentar e implementar políticas informacionais voltadas para formação da competência em informação.
\end{abstract}

Palavras-chave: Ciência; COVID-19; Dimensões da Competência em Informação; Infodemia; Desinformação.

ABSTRACT: This article aims to reflect, based on the Sociology of Science and Information Science, on the conditions of production, dissemination and validation of statements, speeches and scientific facts inside and outside the laboratories. In continuity, it was intended to address information in contemporary society, presenting the concepts of infodemia and disinformation, as well as presenting the possible ways of mobilizing individuals through the dimensions of information competence in the face of the COVID-19 pandemic. As for the methodological procedures, this research is characterized in terms of objectives as exploratory, as far as procedures are concerned, bibliographic research was used. From the data analyzed, we infer that the pandemic demonstrated that a significant portion of the population is vulnerable to infodemia and disinformation. Institutionalized information sources are the best communication channel to reverse this situation. It is concluded that, it becomes more and more urgent to promote and implement informational policies aimed at the formation of information competence.

Keywords: Science; COVID-19; Dimensions of Information Competence; Infodemic; Misinformation.

\footnotetext{
a Programa de Pós-Graduação em Ciência da Informação, Universidade Federal do Espírito Santo, Vitória, ES, Brasil.

b Programa de Pós-Graduação em Gestão de Documentos e Arquivos, Universidade Federal do Estado do Rio de Janeiro, Rio de Janeiro, RJ, Brasil.

*Correspondência para/Correspondence to: Mariana Lousada. E-mail: mariana.lousada@gmail.com.

Recebido em/Received: 08/09/2020; Aprovado em/Approved: 01/12/2020.
}

Artigo publicado em acesso aberto sob licença CC BY 4.0 Internacional $(9)$ 


\section{INTRODUÇÃO}

$\mathrm{Na}$ contemporaneidade, a emergência do novo coronavírus (SARS-CoV-2), que é responsável por causar uma doença respiratória aguda grave (COVID-19), tem provocado reflexões sobre enunciados, fatos científicos e a respeito dos fatores que os circundam. A doença é altamente contagiosa, sendo considerada uma Emergência de Saúde Pública de Importância Internacional (ESPII), que alcançou o registro de 54 075995 casos confirmados, 1303919 mortes e 220 países, áreas ou territórios com casos ao redor do mundo".

Os cientistas de diversas áreas de conhecimento e de variados países estão realizando pesquisas para caracterizar o vírus, seus efeitos, suas formas de transmissão, seus impactos físicos, sua letalidade e, principalmente, para a criação de uma vacina e medicamentos antivirais para a imunização da população e contenção da doença. Com isso, tem-se produzido e disponibilizado diversas informações em âmbito mundial acerca da COVID-19. De acordo com Beldarraín Chaple (2020, p. 2, tradução nossa):

[...] muitos artigos são publicados em tempo real; as revistas mais prestigiadas publicam artigos quase diariamente, no modelo de publicação contínua/corrente. Muitos artigos também são publicados em repositórios de acesso aberto como preprints, ou seja, antes de sua revisão por pares.

Os sistemas e redes de informação - canais formais e informais - podem ser considerados referenciais para o entendimento das múltiplas conexões entre indivíduos e as informações científicas na sociedade, que refletem no processo de isolamento desse agente virológico com o objetivo de controlar sua transmissão e o avanço de seu contágio.

Existem diversas ações sendo realizadas pela Organização Mundial da Saúde (OMS), pela Organização Pan-Americana da Saúde (OPAS), pelas universidades públicas brasileiras e outras instituições de âmbito governamental e privado para auxiliar nos processos de disponibilização de informações científicas acerca da temática. Ressaltam-se que tais instituições têm desenvolvido recursos para facilitar seu acesso, dentre as quais destacam-se os diretórios, repositórios, observatórios, painéis, entre outros.

Para além das informações veiculadas por esses canais formais, deve-se considerar as que são fornecidas por canais informais. Conforme Beldarraín Chaple (2020, p. 01) houve uma quantidade significativa de informações veiculadas por meio da "[...] imprensa, nas notícias, em especiais de rádio e televisão e nas redes sociais". A Organização Mundial da Saúde (2020) pontua que neste momento experiencia-se uma situação em que muitas informações são produzidas e compartilhadas ao redor mundo, alcançando bilhões de pessoas, fazendo inclusive um questionamento acerca da precisão dessas informações.

De acordo com a Organização Mundial da Saúde (2020, p. 2, tradução nossa), “[...] o surto da COVID-19 e a resposta a ele têm sido acompanhados por uma enorme infodemia", ou seja, um excesso de informações, muitas vezes, acompanhada de informações falsas e/ou distorcidas, que agem visando a manipulação da opinião da

\footnotetext{
1 Estes dados foram retirados do site da Organização Mundial da Saúde (OMS) no dia 16/11/20. Disponível em: https://www.who.int/emergencies/diseases/novel-coronavirus-2019?gclid=CjoKCQiA48jgBRC-

ARIsAMQu3WSDoCnCJ3iJcglghXLHdx-2TArNrFBrGo4aYc1kUR-lef3tZA2wKxkaAq65EALw_wcB. Acesso em: 16 nov. 2020 .
} 
população acerca de determinados assuntos. Este aglomerado de informações acerca do vírus pode prejudicar a recuperação de materiais significativos pelos cidadãos, pelos profissionais responsáveis pela tomada de decisão, por profissionais da área de saúde e por cientistas (ORGANIZAÇÃO MUNDIAL DA SAÚDE, 2020).

Assim, parte-se do pressuposto de que, além da disponibilização e acesso às informações, é importante refletir sobre as compreensões, análises críticas e usos realizados pelos indivíduos. Em outras palavras, é preciso pensar nos aspectos inerentes à competência em informação dos indivíduos, visto que podem dar-Ihes respaldo em sua postura perante o enfrentamento da crise causada pelo novo coronavírus auxiliando de diversas formas. Por exemplo, os processos referentes à avaliação de informações disponibilizadas sobre a atual realidade sanitária são recursos importantes para auxiliar os cidadãos no uso destas e na tomada de decisões quanto ao cumprimento das medidas preventivas recomendadas por especialistas, tais como, o distanciamento social, o uso de máscaras, entre outras.

A competência em informação refere-se a processos informacionais, requerendo destrezas para o domínio de atividades instrumentais em diversos âmbitos, ambientes e formatos, bem como de compreensão dos conteúdos informativos visando à construção do pensamento crítico e de conhecimentos para posterior uso em seus contextos pessoais, sociais, sanitários, econômicos e políticos.

Estes elementos de competência em informação estão relacionados à mobilização de ações dos indivíduos para a compreensão da COVID-19 e do processo de emprego das medidas preventivas, que refletirão na posição em que cada localidade ocupará na curva de casos no que se refere ao seu declínio ou sua ascensão.

No Brasil, verifica-se, desde maio de 2020, o agravamento da situação, entre tantos fatores, pela forma como fatos e informações científicas têm sido objeto de disputas entre saber científico e poder político-econômico. Em meio a essas disputas, devido a uma política de governo e não de estado implementada pela esfera federal, aspectos econômicos e políticos recebem destaque em detrimento dos relativos aos direitos dos cidadãos, como os relacionados à vida e à saúde.

Diante do exposto, este artigo tem como objetivo refletir, com base na Sociologia da Ciência e na Ciência da Informação, sobre as condições de produção, divulgação e validação de enunciados, discursos e fatos científicos dentro e fora dos laboratórios. Em continuidade, pretendeu-se abordar a informação na sociedade contemporânea, apresentando as concepções de infodemia e desinformação, bem como apresentar as possíveis formas de mobilização dos indivíduos por meio das dimensões da competência em informação frente à pandemia da COVID-19.

Neste sentido, essa pesquisa se caracteriza quanto aos objetivos como exploratória, que [...] têm como principal finalidade desenvolver, esclarecer e modificar conceitos e ideias, tendo em vista a formulação de problemas mais precisos ou hipóteses pesquisáveis para estudos posteriores" (GIL, 2008, p. 27). Isto é, investiga-se a informação a partir de um olhar pautado na ciência em uma sociedade que tem como problemática o excesso de informações (infodemia) e a proliferação acelerada de informações falsas e/ou distorcidas no que se refere à COVID-19, causando o que vem sendo caracterizado como desinformação. Para lidar com este contexto, acredita-se que é necessário o desenvolvimento e/ou aprimoramento da competência em informação pelos indivíduos em suas diversas dimensões.

No que se refere aos procedimentos para a construção do corpus deste estudo, utilizou-se a pesquisa bibliográfica, realizando-se um levantamento de artigos na Base de Dados Referencial de Artigos de Periódicos em Ciência da Informação (BRAPCI) e 
no Google Acadêmico em busca de materiais que abordassem a desinformação, a infodemia, a competência em informação e a pandemia da COVID-19. Os livros foram utilizados para subsidiar a discussão a partir de um viés científico e social. No que diz respeito às informações técnico-científicas sobre a COVID-19, foram usados o site do Ministério da Saúde, da OMS, OPAS, do Monitora Covid da Fundação Oswaldo Cruz (FIOCRUZ), do Observatório da COVID-19 (FIOCRUZ), do Centro Latino-Americano e do Caribe de Informação em Ciências da Saúde (BIREME) e o Portal de Periódicos da Coordenação de Aperfeiçoamento de Pessoal de Nível Superior (CAPES).

$\mathrm{Na}$ análise dos resultados, visou-se realizar uma discussão sobre o objeto da pesquisa a partir das fontes de informação encontradas na literatura em diferentes campos do saber, bem como daquelas de natureza técnico-científicas. Pela Sociologia da Ciência e pela Ciência da Informação, considerou-se a relevância dos produtos resultantes dos laboratórios e da divulgação científica para que os conhecimentos produzidos sobre a realidade estudada possam ser avaliados e validados pela sociedade. Por esse encaminhamento, as análises foram realizadas no sentido da sua institucionalização (produção, custódia, organização e/ou formas de divulgação) e pelas possibilidades de usos perante procedimentos e ferramentas de avaliação, atentando para os fundamentos da competência em informação.

Os conhecimentos advindos das pesquisas de cunho científico dão legitimidade para a compreensão quanto à caracterização do novo coronavírus, seus efeitos, impactos, formas de transmissão e de controle, bem como às novas descobertas, principalmente nos âmbitos sanitários, sociais e econômicos. Considera-se que neste contexto é essencial saber lidar com os processos que envolvem a competência em informação, de modo a conseguir fazer a distinção de informações provenientes desta situação infodêmica e dos movimentos de desinformação e de manipulação da opinião pública no que se refere à COVID-19.

\section{PRODUÇÃO, DIVULGAÇÃO E VALIDAÇÃO DE FATOS CIENTÍFICOS}

A legitimação da existência da COVID-19 no Brasil, observada enquanto doença, estado de pessoas doentes e/ou vetores para a transmissão, tem sido objeto de disputa entre diferentes comunidades discursivas. Um dos aspectos desse embate é a forma como cada qual operacionaliza enunciados e discursos sobre um fato científico por meio de certos regimes de verdade e de informação. Essa perspectiva de análise dialoga com os estudos de Fleck (2010) a respeito da ampla gênese do conceito sífilis, os quais sustentam reflexões científico-sociais sobre designações e delimitações de doenças diferenciadas bem como de seus sintomas, que no caso do presente trabalho é a COVID-19.

Como fato científico compreende-se um enunciado objetivo e instituído, a partir de vinculações históricas, que permite maior estabilidade para a validação de uma existência, por exemplo, de um novo coronavírus (FLECK, 2010). Dada a condição inaugural e a força de circulação do SARS-CoV-2, entram em cena elementos que geram instabilidade suficiente para que os enunciados científicos sejam mais suscetíveis a contestações e alocações.

Importante destacar que os enunciados científicos, que instituem fatos científicos, não são impermeáveis. Isso deve-se a diversos fatores, como as transformações das descobertas e as dificuldades de estabilização de agentes virológicos que não ficam isolados em laboratórios. Dessa forma, cabe a compreensão de que a atual entidade nosológica (COVID-19), os sintomas e os estados patológicos dos doentes requerem 
um longo percurso de entendimentos e práticas "[...] e não uma única solução lógica ou objetiva." (FLECK, 2010, p. 63).

Na concepção de Fleck (2010, p. 64), é complexa a diferenciação entre o concreto e o abstrato, pois "Na realidade não existem doenças, mas apenas pessoas doentes." Para Condé (2010, p. xiv), as abordagens de Fleck desafiam as compreensões sobre fatos científicos, na medida em que os apresenta como derivados do social e não da lógica, analisando seu surgimento e desenvolvimento a partir de um "sistema de referências" por meio do qual uma multiplicidade de "conexões passivas" e "conexões ativas" se equilibram.

Latour e Woolgar (1997) afirmam que fatos e realidades são consequências, e não causas, do trabalho científico, indicando para a importância do momento em que as coisas acontecem. A aceitação de uma realidade como fato deve-se, entre outros fatores, a validade de um enunciado científico fora do laboratório. Portanto, o caráter objetivo de um fato científico pode ser observado no trabalho do laboratório, mas sua aceitação e legitimidade dá-se fora do laboratório, configurando uma realidade exterior ou um caráter operacional. Para os autores, dada realidade estrutura-se por meio de um

[...] processo pelo qual o enunciado torna-se fato, uma vez que é somente depois que ele se tornou um fato que surge o efeito de realidade. Isso se produz caso o efeito de realidade se apresente em termos de 'objetividade', de exterioridade. (LATOUR; WOOLGAR, 1997, p. 199).

O trabalho realizado nos laboratórios é materializado em documentos de diferentes naturezas, os quais são elaborados, em um primeiro momento, para registrar o percurso das investigações e descobertas. Em um segundo momento, são produzidos documentos para comunicar os resultados das pesquisas, seja para a comunidade científica ou para a sociedade em geral.

Em Fleck, são identificados três tipos de bibliografia da ciência especializada: os periódicos, os manuais e os livros didáticos. Os primeiros são marcados pela provisoriedade no tratamento dos problemas, condizente com os materiais e recursos técnicos disponíveis, visando a transição da fase experimental para a da certeza objetiva. Já, os manuais operam com a sistematização dos saberes presentes nos periódicos, omitindo certos embates e simplificando as discussões entre os especialistas, para se tornarem mais compreensíveis. De forma similar, os livros didáticos possuem linguagem mais acessível e finalidade pedagógica (SCHÄFER; SCHNELLE, 2010).

Por meio desses e outros dispositivos para a comunicação científica, verifica-se que a interação entre o que está estabilizado dentro do laboratório com as possibilidades de estabilização fora do laboratório é um processo dinâmico de articulações para normalização da ciência. Em muitos casos, a aceitação de um fato científico está condicionada à dadas conjunturas (políticas, econômicas, sociais e culturais) que refletem na recepção, entendimento e formas de apropriação. Para Foucault (1979, p. 12),

A verdade é deste mundo; ela é produzida nele graças a múltiplas coerções e nele produz efeitos regulamentados de poder. Cada sociedade tem seu regime de verdade, sua "política geral" de verdade: isto é, os tipos de discurso que ela acolhe e faz funcionar como verdadeiros; os mecanismos e as instâncias que permitem distinguir os enunciados verdadeiros dos falsos, a maneira como 
sanciona uns e outros; as técnicas e procedimentos que são valorizados para a obtenção da verdade; o estatuto daqueles que têm o encargo de dizer o que funciona como verdadeiro.

A partir das reflexões de Foucault e em diálogo com Frohmann (2004), cabe a compreensão de que o produto de um discurso científico tem por trás de si instituições, relações sociais, técnicas, práticas, discursos, enfim, uma série de elementos que fazem com que este não seja um produto do senso comum.

Um produto científico resulta de relações e cultura próprias, as quais validam, pelo percurso temporal e espacialmente localizável, as práticas de investigações e enunciações sobre objetos e eventos. Do mesmo modo, as inscrições e comunicações resultantes desses lugares de práticas científicas são construções da ciência no processo de busca do conhecimento e da verdade. Em outros termos, os documentos são a materialização de um saber localizável, interpretado, produzido e inscrito segundo dadas normas e padrões que prescrevem traços e traçados da produção científica e de sua comunicação (FROHMANN, 2004).

Frohmann (2004) adverte que o saber científico, os discursos produzidos sobre ele e a verdade científica estão abertos para o porvir para que possam ser respondidos ou finalizados no futuro. $\mathrm{O}$ autor chama atenção à importância da literatura científica em estabilizar fenômenos científicos, que pode minimizar dúvidas razoáveis. Ou seja, esses saberes, dada a sua divulgação, estão permeáveis a controvérsias, contestações e identificação de erros que podem ser objeto de verificação e atualização. Entretanto, o que cabe nesse processo de intercâmbios entre informações científicas e dispositivos de mediação é a competência para identificar os seus usos políticos.

Não há saber neutro. Todo saber é político. E isso não cai nas malhas do Estado, é apropriado por ele, que dele se serve como instrumento de dominação, descaracterizando seu núcleo essencial. Mas porque todo saber tem sua gênese em relações de poder. Assim, o fundamental desta análise é que saber e poder se implicam mutuamente: não há relação de poder sem constituição de um campo de saber, como também, reciprocamente, todo saber constitui novas relações de poder (MACHADO, 1979, p. xxi).

A partir desses apontamentos, verifica-se que os produtos informativos resultantes do conhecimento científico estabilizam variados elementos que, embora estejam sujeitos a contestação e não legitimação no meio social, possuem um status diferencial. Esses são produzidos dentro de regimes de verdade e de informação que dão "[...] peso, massa, inércia e estabilidade[...]” à informação científica (FROHMANN, 2008, p. 24).

Frohmann (2008), ao acompanhar os pensamentos de Fleck e Latour, aborda a necessidade da materialização da informação por meio de práticas que concedam aos enunciados possibilidades de sobrevivência em meio a controvérsias. Tal condição, mesmo que esteja permeável a diversas verificações e usos, possui recursos para suportar as investidas contrárias que não se estruturam por meio de aportes similares - aos científicos - para a produção de enunciados funcionais sobre fatos e realidades do cotidiano.

Desse modo, entre as disputas de relações de forças, os movimentos contrários às configurações científicas podem parecer, à primeira vista, não ter um efeito durável e serem apenas circunstanciais. Contudo, pela maneira como a "realidade" da atual pandemia tem sido conduzida em algumas localidades, como no Brasil, e dos dispositivos de contradição que estão sendo acionados, esses movimentos requerem uma atenção especial. 
Foucault (1979, p. 141-142) adverte que o exercício do poder “[...] cria objetos de saber, os faz emergir, acumula informações e as utiliza. [...] cria perpetuamente saber, e, inversamente, o saber acarreta efeitos de poder". Entende-se, então, que um dos caminhos para o tratamento dos embates entre diferentes comunidades discursivas que operam sobre fatos científicos é por meio do desenvolvimento de competências em diferentes dimensões pelos usuários da informação científica para identificação de vetores de forças (políticos, econômicos, sociais).

Nesse sentido, os profissionais em informação precisam operar com os diversos fatores que influenciam em qualquer atividade do conhecimento: a tradição, a educação, a atmosfera social, entendimentos de uma época, políticas e possibilidades de legitimação. Fleck (2010, p. 91-92) apresenta que "A experiência científica decorre de condições particulares, históricas e socialmente dadas. Estamos sendo treinados para ela, mas ela não nos é simplesmente acessível.".

Pela concepção de Latour (2000, p. 357), o “[...] 'conhecimento' não é algo que possa ser descrito por si mesmo ou por oposição a 'ignorância' ou 'crença', mas apenas por meio do exame de todo um ciclo de acumulação [...]". Portanto, para a experiência e a vivência em conjunturas como a da atual pandemia, pode haver uma formação para que os conhecimentos sobre "existências" e realidades sejam mais acessíveis e auxiliem nos processos de tomadas de decisões. Eis uns dos desafios da contemporaneidade: a compreensão das redes de produção e divulgação de informações científicas confiáveis e a maneira como os seus usos e validação pela sociedade impactam nas práticas de controle da COVID-19.

\section{INFORMAÇÃO NA SOCIEDADE EM CONTEXTO PANDÊMICO}

As novas formas de produção, disseminação e comunicação da informação e do conhecimento, surgidas a partir da segunda metade do século $\mathrm{XX}$, impulsionadas pela globalização, uso de tecnologias e desenvolvimentos de sistemas de comunicação em massa, fizeram com que a informação se ampliasse de maneira descontrolada (ALFONSO SÁNCHEZ; FERNÁNDEZ VALDÉS, 2020).

Os fluxos informacionais, formais e informais, se reproduzem todos os dias, o desenvolvimento e uso de plataformas digitais, redes sociais, blogs, favorecem o acesso a conteúdos pelos cidadãos de maneira rápida. A disponibilização e acesso a esse universo informacional não significa que essas fontes são confiáveis, quando se trata de informações "não formais", ou seja, que advém de fontes não avaliadas ou validadas, tornando-se responsabilidade do indivíduo avaliar antes de utilizar e disseminar.

Em períodos graves, como o da pandemia da COVID-19, a sobrecarga de informações ganha contornos mais complexos, e tem mobilizado diversas entidades no combate ao que se tem denominado de "infodemia", que se refere a um grande aumento no volume de informações associadas a um assunto específico, que podem se multiplicar exponencialmente em pouco tempo devido a um evento específico, como a pandemia atual. Definida pela Organização Mundial da Saúde (2020) como um "dilúvio de informações - precisas ou não - que dificultam o acesso a fontes e orientações confiáveis".

A infodemia pode agravar mais o cenário experienciado diante da pandemia da COVID19. A Organização Pan-Americana de Saúde e a Organização Mundial de Saúde (2020, p. 3, grifo nosso) aponta uma série de situações: 


\begin{abstract}
- Ela dificulta que fontes idôneas e orientações confiáveis sejam encontradas pelas pessoas de modo geral, pelos responsáveis pela tomada de decisões e por profissionais de saúde quando precisam. As fontes podem ser aplicativos, instituições científicas, sites, blogs, "influenciadores", entre outras.

- As pessoas podem se sentir ansiosas, deprimidas, sobrecarregadas, emocionalmente exaustas e incapazes de atender a demandas importantes.

- Ela pode afetar os processos de tomada de decisões quando se esperam respostas imediatas e não se dedica tempo suficiente para analisar com cuidado as evidências.

- Não há controle de qualidade do que é publicado nem, às vezes, do que é usado para agir e tomar decisões.

- Qualquer pessoa pode escrever ou publicar qualquer coisa na rede (podcasts, artigos, etc.), principalmente nos canais das redes sociais (contas de indivíduos e instituições).
\end{abstract}

Sendo assim, a infodemia pode afetar diretamente a compreensão e a avaliação dos indivíduos do que são informações verdadeiras e confiáveis e levar ao surgimento de rumores e desinformação, bem como a manipulação de informações com intenção duvidosa.

A desinformação é outro aspecto que deve ser considerado quando estamos lidando com a infodemia, isto porque trata-se de uma "informação falsa ou imprecisa cuja intenção deliberada é enganar" (ORGANIZAÇÃO PAN-AMERICANA DE SAÚDE; ORGANIZAÇÃO MUNDIAL DA SAÚDE, 2020). Ainda, segundo Brito e Pinheiro (2015, p. 6) a "[...] desinformação é considerada uma ação proposital para desinformar alguém, de maneira a enganá-lo".

No relatório Tackling the Information Crisis: a Policy Framework for Media System Resilience, elaborado pela London School of Economics and Political Science (LONDON..., 2018, p. 10, tradução nossa), foi estabelecido cinco grandes males relacionados a desinformação enfrentados pelos governos, parlamentos, empresas de tecnologia e todos os participantes do sistema midiático do século XXI:

\footnotetext{
- Confusão: ocorre quando os cidadãos tem menos certeza do que é verdade e, também, se sentem confusos acerca de quem acreditar/confiar;

- Cinismo: os cidadãos estão perdendo a confiança, mesmo em fontes de informação consideradas confiáveis.

- Fragmentação: os cidadãos têm acesso a um conhecimento infinito, porém o conjunto de fatos consensuais sobre os quais basear suas escolhas está diminuindo, tornando-se cidadãos divididos, com realidades e narrativas paralelas.

- Apatia: os cidadãos estão desvinculando-se das estruturas sociais estabelecidas e perdendo a fé na democracia.

- Irresponsabilidade: o poder sobre o conhecimento é mantido por organizações que não possuem um código de responsabilidade ética desenvolvido e não seguem linhas objetivas no que tange à responsabilidade social e transparência.
}

Em uma pandemia, a desinformação pode afetar profundamente todos os aspectos da vida e, mais especificamente, a saúde mental das pessoas. Por esta razão, destaca-se a importância das fontes de informação institucionalizadas, advindas de organizações específicas voltadas para a área de saúde, órgãos científicos e governamentais para a difusão de informações confiáveis. 
Nesse sentido, podemos destacar diversos exemplos de fontes de informação gerais e especializadas sobre COVID-19 que buscam facilitar o acesso à informação técnicocientífica e promover a circulação do conhecimento entre os pesquisadores, profissionais, estudantes e a comunidade:

- Ministério da Saúde: painel com informações sobre o avanço da COVID-19 nos municípios e estados do país.

- OPAS/OMS: portal com informações gerais e especializadas sobre a pandemia na América.

- MonitoraCovid-19 (Icict/Fiocruz): agrupa e integra dados sobre a pandemia no Brasil e no mundo. A ferramenta está disponível em acesso aberto e pode ser utilizada por toda a comunidade científica, profissionais de saúde e demais interessados.

- Observatório Covid-19 (Fiocruz): desenvolve análises integradas, tecnologias, propostas e soluções para enfrentamento da pandemia por Covid-19 pelo SUS e pela sociedade brasileira.

- BIREME: Vitrine de conhecimento sobre COVID-19, com informação científica, notificações de casos, guias e orientações para profissionais, plano de contingência e protocolo de manejo clínico etc. Inclui fontes de informação para a pesquisa e informações dos países da América Latina e Caribe, América do Norte e Península Ibérica.

- Portal de Periódicos da Capes: Acesso aos conteúdos nas notícias do portal ou pela opção buscar base, pela busca por editor ou base de dados.

- IBICT: Diretório de fontes de informação científica de livre acesso sobre o coronavírus lançado pelo IBICT. Inclui bases de artigos e revistas, teses e dissertações, dados de pesquisa, relatórios e evidências, repositórios de pré-prints e outras informações.

Essas são só algumas das iniciativas que buscam garantir a disseminação e veracidade da informação oficial comunicada a sociedade através do intercâmbio de pesquisadores e profissionais visando enfrentar a infodemia e a desinformação. A disponibilização e o acesso às informações de qualidade são centrais para o combate a pandemia, por meio de portais, sites, aplicativos e outros recursos disponibilizados pelo governo e pelas instituições é que os cidadãos podem consumir informações confiáveis e de credibilidade.

A infodemia e a desinformação são grandes desafios enfrentados durante a pandemia da COVID-19, e tem como base a carência de competências informacionais (conhecimentos, habilidades e atitudes para o uso e interpretação adequada da informação), cabe aos governos implementarem políticas informacionais em colaboração com instituições científicas, universidades e com os meios de comunicação para a formação dessas competências nos indivíduos.

\section{AS DIMENSÕES DA COMPETÊNCIA EM INFORMAÇÃO E A PANDEMIA DO NOVO CORONAVÍRUS}

O termo Information Literacy teve várias traduções para o português do Brasil, como competência em informação, competência informacional, letramento informacional, alfabetização em informação, habilidades informacionais e, o termo mais recente, competência crítica em informação. De acordo com Belluzzo (2017, p. 57) “[...] a 
definição do termo ainda traz consigo inúmeras discussões na literatura especializada, tanto nacional quanto internacional". Neste artigo, optou-se pelo uso do termo competência em informação, visto compreender que tem adquirido maior consenso no cenário nacional.

Para Uribe Tirado (2009), o conceito de competência em informação engloba um processo holístico, que inclui determinados comportamentos e é integrado a outras competências, ratificando as tendências de estudos atuais voltados para as multicompetências, metacompetências ou transcompetências em âmbito mundial. Sendo assim, "[...] outras competências com enfoques distintos e complementares podem ser trabalhadas de modo conjunto com a competência em informação como, por exemplo, a competência midiática e a leitora" (MATA; GERLIN, 2019).

A competência em informação está ligada a processos referentes à busca de informações, que é quando os indivíduos se predispõem à procurá-las para sanar uma necessidade ou um problema com intencionalidade de resolvê-lo, à avaliação crítica e ao uso responsável da informação na sociedade, por meio da análise de suas características como fonte de informação e como representação social, bem como à construção de conhecimentos e ao pensamento crítico, que podem propiciar a emancipação e consciência coletiva dos indivíduos para exercer seus direitos e deveres na sociedade.

Diante do contexto, a realização de ações de competência em informação torna-se imprescindível diante da situação infodêmica presenciada na conjuntura atual, marcada pela alta produção e disseminação de informações acerca do novo coronavírus nos diversos meios e ambientes, que concorrem entre as informações de cunho científico, senso comum e notícias falsas e/ou distorcidas, afetando diretamente à sociedade e às condições sanitárias recomendadas para a prevenção contra o vírus. De acordo com Orelo e Vitorino (2012, p. 45):

[...] a Competência Informacional, quando desenvolvida adequadamente, além de capacitar os indivíduos (usuários de bibliotecas, profissionais, crianças, jovens, adultos e outros grupos) para utilização dos recursos informacionais, promove o interesse pela aprendizagem contínua e pode favorecer a evolução cognitiva, a curiosidade e a investigação criadora e pode contribuir, ainda, para uma "navegação" mais equilibrada no complexo fenômeno informacional.

Para corroborar com essas questões, partem-se dos fundamentos das quatro dimensões da competência em informação elaboradas por Vitorino e Piantola (2011): a técnica, a estética, a ética e a política. Essas dimensões foram desenvolvidas por meio de reflexões educacionais e filosóficas, que estão interligadas, possibilitando ter um panorama dos aspectos inerentes à competência em informação dos indivíduos no que se refere à apreensão dos elementos que permeiam este cenário de pandemia e as relações que envolvem as esferas científicas, sanitárias, sociais, políticas e econômicas.

A dimensão técnica possui viés pragmático, se refere a uma ação empreendida em um determinada situação, por exemplo: buscar os recursos e fontes de informação acerca do novo coronavírus; avaliar o conteúdo desta informação criticamente, de modo a analisar sua fidedignidade, confiabilidade, credibilidade e autenticidade; usar a informação necessária para sanar suas dúvidas e; quando necessário, comunicar essa informação de maneira responsável em seus espaços de vivência, em suas mídias sociais, entre outros. 
A dimensão estética está ligada à arte que, por sua vez, tem relação com a sensibilidade, criatividade, intuição, harmonia e beleza. Refere-se à capacidade de compreender, relacionar, ordenar, configurar e ressignificar a informação, ou seja, é uma experiência interior, cognitiva, individual e única do sujeito ao lidar com os conteúdos de informação e sua maneira de expressá-la e agir sobre ela no âmbito coletivo (VITORINO; PIANTOLA, 2011).

Ainda de acordo com Orelo e Cunha (2013), essa dimensão "[...] está associada à possibilidade de construção de conhecimento, pois as percepções de cada indivíduo, contribuem para formar um corpus de conhecimentos." Neste sentido, estimula-se o pensamento crítico dos indivíduos para distinguir as informações de cunho científico, do senso comum e as informações falsas e/ou distorcidas. Procura-se compreender e adquirir novos conhecimentos nas questões referentes ao novo coronavírus, criando uma visão sensível e de natureza humanística dos impactos sociais e econômicos ocasionados pelo mesmo, bem como as ações coletivas para prevenção e controle da pandemia.

A dimensão ética diz respeito ao uso responsável da informação, visando o bem comum, está inclusa uma abordagem ligada à apropriação, ao uso da informação e à propriedade intelectual, aos direitos autorais, ao acesso à informação e à preservação da memória do mundo (VITORINO; PIANTOLA, 2011). Neste sentido, reflete-se sobre o uso coletivo da informação, contemplando as ações de compartilhamento de informações falsas e/ou distorcidas - que dizem respeito ao novo coronavírus, que causam impactos sanitários e sociais, culminando em um contexto de infodemia, desinformação e aumento na transmissão da doença. Conforme Mata e Gerlin (2019, p. 5):

[...] estamos vivenciando um contexto rodeado por informações que possuem como finalidade causar desinformação, que como consequência já tem provocado grandes impactos em vários setores por meio da manipulação de opiniões de população em larga escala, fazendo com que as pessoas duvidem da confiabilidade de informações verdadeiras ao invés desconfiar daquelas manipuladas ou distorcidas [...].

Ressaltam-se também condutas referentes à propriedade intelectual, visando-se ter cuidado com a divulgação de imagens e de conteúdos, atribuindo-se os devidos créditos aos criadores/autores, assim como sua contextualização. Faz-se necessário considerar que as ações exercidas possuem efeitos, que podem vir a prejudicar, em um nível micro, comunidades e cidades inteiras e, em nível macro, diversos países.

A dimensão política está relacionada ao exercício de cidadania e aos direitos e deveres dos indivíduos, a sua participação nas decisões e nas transformações referentes à vida social, considerando que a informação é produzida a partir de (e em) um contexto específico (VITORINO; PIANTOLA, 2011). Aqui incluem-se os aspectos referentes aos usos da informação na sociedade e suas relações de poder em determinadas conjunturas, compactuando para o agravamento de uma das situações sanitárias mais graves vivenciadas na história da humanidade.

Ao discorrer sobre as dimensões políticas, é importante contextualizar as diversas situações presenciadas neste período pandêmico, que consistem no trabalho de cientistas em busca por uma vacina e antivirais para prevenir, tratar e interromper a difusão da COVID-19, em informações perpetuadas a partir do senso comum e da desinformação e dos direitos e deveres dos indivíduos neste contexto. 
No que tange aos direitos e deveres dos indivíduos neste contexto, pode-se dizer que estão ligadas às recomendações da OMS e do Ministério da Saúde pautadas em informações de cunho científico. Por um lado, todos os indivíduos devem ter acesso às fontes e recursos formais e informais para compreender o que o novo coronavírus representa, sua facilidade de propagação e seus sintomas, bem como saber o que fazer se ficar doente e em que casos devem procurar por unidades de saúde. Por outro, devem cumprir com as recomendações e medidas preventivas, empreendendo diversas ações para proteger a si e aos outros, usando os equipamentos de proteção individual, higiene adequada, com ênfase no distanciamento social, visto que são fundamentais para a contenção do vírus, ressaltando-se que não há vacinas até o momento, conforme mencionado.

Neste sentido, corroborando com as dimensões da competência em informação mencionados, a Organização Pan-Americana de Saúde e a Organização Mundial de Saúde (2020, p. 3) explanam alguns comportamentos diante deste universo informacional que podem auxiliar no combate à infodemia da COVID-19, que são:

Figura 1: Ações de combate à desinformação

\begin{tabular}{|c|c|c|c|}
\hline $\begin{array}{l}\text { Confie na } \\
\text { OMS }\end{array}$ & Identifique as evidências & Evite as fake news & Apoie a ciência aberta \\
\hline \multicolumn{3}{|c|}{$\begin{array}{l}\text { Verifique se a informação realmente faz sentido, mesmo que seja de uma fonte } \\
\text { segura e já tenha sido compartilhada }\end{array}$} & $\begin{array}{l}\text { Denuncie os rumores } \\
\text { prejudiciais }\end{array}$ \\
\hline $\begin{array}{l}\text { Proteja a } \\
\text { privacidade }\end{array}$ & $\begin{array}{l}\text { Abra os dados } \\
\text { (de qualidade) }\end{array}$ & \multicolumn{2}{|c|}{$\begin{array}{l}\text { Se você não tem como confirmar a fonte da informação, sua utilidade, ou } \\
\text { se já foi compartilhada antes... } \\
\text { é melhor não compartilhar }\end{array}$} \\
\hline \multicolumn{2}{|c|}{$\begin{array}{l}\text { Confirme se a informação já foi compartilhada antes por } \\
\text { outras pessoas }\end{array}$} & \multicolumn{2}{|c|}{$\begin{array}{c}\text { Participe de conversas sociais com } \\
\text { responsabilidade }\end{array}$} \\
\hline $\begin{array}{l}\text { Continue a } \\
\text { colaborar }\end{array}$ & $\begin{array}{l}\text { Compartilhe informações } \\
\text { com responsabilidade }\end{array}$ & \multicolumn{2}{|c|}{$\begin{array}{l}\text { Confirme a fonte, sobretudo em conversas no } \\
\text { WhatsApp }\end{array}$} \\
\hline \multicolumn{3}{|c|}{ Se a informação não for confirmada, é melhor não compartilhar } & Continue aprendendo \\
\hline
\end{tabular}

Fonte: Organização Pan-Americana de Saúde e Organização Mundial da Saúde (2020)

Compreende-se que ao planejar as ações direcionadas à competência em informação, deve-se entender os contextos em que os indivíduos estão inseridos, considerando ambientes familiares, comunitários, profissionais, sanitários, sociais, econômicos, culturais e políticos, visto que possuem influência em seus saberes e fazeres no que se refere à pandemia, dando sentido às suas práticas e/ou formas de mobilização, que podem, por sua vez, auxiliar controle da COVID-19.

\section{CONSIDERAÇÕES FINAIS}

Os entendimentos sobre os processos que permeiam a produção e legitimação de fatos científicos apontam para as dinâmicas próprias dos saberes e fazeres dentro dos laboratórios e para as formas de recepção e apropriação em um corpus social mais amplo. Assim, observa-se a existência de padrões e normas que auxiliam na verificação da confiabilidade de determinados dispositivos de comunicação em detrimento de outros.

Pelos traços e traçados do trabalho científico e dos meios de divulgação das informações correlatas pode-se ter, senão a verdade científica finalizada, o caminho percorrido por especialistas para a sua formulação. Importante nesse percurso, a consciência de que existem vetores de forças (políticos, econômicos, sociais) que 
podem ser articulados para desautorizar os resultados dos produtos científicos, muitos desses pautados em elaborações que se aproximam do senso comum ou de investidas políticas intencionais.

Em meio aos tantos movimentos que podem ser verificados na atualidade, onde diferentes comunidades discursivas buscam produzir ou compartilhar informações que, em sua essência tiveram sua gênese nos trabalhos dos laboratórios, os desafios assinalam para os usos das informações e seus desdobramentos.

A infodemia e a desinformação se tornaram agravadores da crise provocada pela COVID-19. Em um contexto informacional e tecnológico que possibilita a circulação e compartilhamento de informações em poucos segundos, temos visto o crescimento descontrolado de informações falsas sobre as formas de contaminação do vírus, de prevenção, a efetividades e utilização de tratamentos, até o questionamento do número de mortos.

Diante dessa situação complexa que implica diretamente na saúde dos cidadãos, é necessário tomar decisões baseadas em evidências científicas. A infodemia e a desinformação se proliferam porque existe uma parcela grande da população que precisam aprimorar suas competências informacionais.

Ações voltadas para a competência em informação são essenciais para enfrentar este período de pandemia, contribuindo para o direcionamento das buscas por fontes e recursos informacionais confiáveis, ao uso crítico e responsável no que tange à produção e compartilhamento de informações, de modo que auxilie no combate à infodemia e à desinformação na sociedade.

\section{REFERÊNCIAS}

ALFONSO-SÁNCHEZ I, FERNÁNDEZ-VALDÉS M. Comportamiento informacional, infodemia y desinformación durante la pandemia de COVID-19. Anales de la Academia de Ciencias de Cuba, v. 10, n. 2, 2020. Disponível em: http://www.revistaccuba.cu/index.php/revacc/article/view/882. Acesso em: 11 ago. 2020.

BELDARRAÍN CHAPLE, E. La información científica confiable y la COVID-19. Revista Cubana de Información en Ciencias de la Salud, v. 31, n. 3, p.1-6, 2020.

BELLUZZO, R. C. B. O estado da arte da competência em informação (COINFO) no Brasil: das reflexões iniciais à apresentação e descrição de indicadores de análise. Revista Brasileira de Biblioteconomia e Documentação, São Paulo, v. 13, n. esp., p. 4776, jan./jul. 2017.

BRITO, V. P.; PINHEIRO, M. M. K. Poder informacional e desinformação. In: ENCONTRO NACIONAL DE PESQUISA EM CIÊNCIA DA INFORMAÇÃO, 16., 2015, João Pessoa. Anais eletrônicos... João Pessoa, PB: ANCIB; UFPB, 2015. Disponível em: http://www.ufpb.br/evento/index.php/enancib2015/enancib2015/paper/view/2677. Acesso em: 02 jul. 2020.

CONDÉ, M. L. L. Prefácio à edição brasileira: um livro e seus prefácios: de pé de página a novo clássico. In: FLECK, Ludwik. Gênese e desenvolvimento de um fato científico. Belo Horizonte: Fabrefactum, 2010. p. vii-xvi. 
FLECK, L. Gênese e desenvolvimento de um fato científico. Belo Horizonte: Fabrefactum, 2010.

FOUCAULT, M. Microfísica do poder. Rio de Janeiro: Edições Graal, 1979.

FROHMANN, B. Deflating information: from science to documentation. Toronto: University of Toronto Press, 2004.

FROHMANN, B. O caráter social, material e público da informação. In: FUJITA, M.;

MARTELETO, R.; LARA, M. (Org.). A dimensão epistemológica da ciência da informação e suas interfaces técnicas, políticas e institucionais nos processos de produção, acesso e disseminação da informação. São Paulo: Cult. Acadêmica; Marília: Fundepe, 2008. p. 19-34.

GIL, A. C. Métodos e técnicas de pesquisa social. 6. ed. São Paulo: Atlas, 2008.

LATOUR, B. Ciência em ação: como seguir cientistas e engenheiros sociedade afora. São Paulo: Editora UNESP, 2000.

LATOUR, B; WOOLGAR, S. A vida de laboratório: a produção dos fatos científicos. Rio de Janeiro: Relume Dumara, 1997.

LONDON SCHOOL OF ECONOMICS AND POLITICAL SCIENCE (LSE). Tackling the information crisis: a policy framework for media system resilience. Reino Unido: LSE, 2018. Disponível em: http://www.Ise.ac.uk/law/news/2018/truth-trust-technology. Acesso em: 30 jul. 2020.

MACHADO, R. Introdução: por uma genealogia do poder. In: FOUCAULT, Michel. Microfísica do poder. Rio de Janeiro: Edições Graal, 1979. p. vii-xxiii.

MATA, M. L.; GERLIN, M. N. M. Programa para a formação em competência em informação visando uma educação que auxilie no combate à desinformação: enfoque nos critérios de avaliação da informação e de fake news. In: ENCONTRO NACIONAL DE PESQUISA EM CIÊNCIA DA INFORMAÇÃO, 20., 2019, Florianópolis-SC. Anais eletrônicos... Florianópolis-SC: ANCIB; PPGCI/SC, 2019. Disponível em: https://conferencias.ufsc.br/index.php/enancib/2019/paper/view/1143/501. Acesso em: 30 jul. 2020.

ORELO, E. R. M.; CUNHA, M. F. V. O bibliotecário e a competência informacional. Informação \& Estudos, v. 23, n. 2, p. 25-32, maio/ago. 2013. Disponível em: https://brapci.inf.br/index.php/res/v/91351. Acesso em: 04 ago. 2020.

ORELO, E. R. M.; VITORINO, E. V. Competência informacional: um olhar para a dimensão estética. Perspectivas em Ciência da Informação, v. 17, n.4 , p. 41-56, out./dez. 2012. Disponível em: https://brapci.inf.br/index.php/res/download/48102. Acesso em: 04 ago. 2020.

ORGANIZAÇÃO MUNDIAL DA SAÚDE - OMS. Novel Coronovirus (2019-nCoV). Situation Report, n. 13, 02. fev. 2020. Disponível em: https://www.who.int/docs/default-source/coronaviruse/situation-reports/20200202sitrep-13-ncov-v3.pdf?sfvrsn=195f4010_6. Acesso em: 13 ago. 2020. 
ORGANIZAÇÃO PAN-AMERICANA DA SAÚDE - OPAS; ORGANIZAÇÃO MUNDIAL DA SAÚDE - OMS. Entenda a infodemia e a desinformação na luta contra a COVID-19. Página Informativa, n. 5, 2020. Disponível em:

https://iris.paho.org/bitstream/handle/10665.2/52054/Factsheet-Infodemic_por.pdf? sequence $=14$. Acesso em: 07 jul. 2020.

SCHÄFER, L.; SCHNELLE, T. Introdução: fundamentação da perspectiva sociológica de Ludwick Fleck na teoria da ciência. In: FLECK, Ludwik. Gênese e desenvolvimento de um fato científico. Belo Horizonte: Fabrefactum, 2010. p. 1-36.

SISTEMA ÚNICO DE SAÚDE - SUS. Sistema Único de Saúde (SUS): estrutura, princípios e como funciona. 2020. Disponível em: http://www.saude.gov.br/sistema-unico-desaude. Acesso em: 31 jul. 2020.

URIBE TIRADO, A. Interrelaciones entre veinte definiciones-descripciones del concepto de alfabetización en información: propuesta de macro-definición. ACIMED, v. 20, n. 4, p. 1-22, 2009.

VITORINO; E. V.; PIANTOLA, D. Dimensões da competência informacional (2). Ciência da Informação, Brasília, DF, v. 40 n. 1, p.99-110, jan./abr. 2011. 